\title{
Bench-to-bedside review: Molecular pharmacology and clinical use of inert gases in anesthesia and neuroprotection
}

\author{
Robert Dickinson ${ }^{1,2 *}$ and Nicholas P Franks ${ }^{1,2}$
}

\begin{abstract}
In the past decade there has been a resurgence of interest in the clinical use of inert gases. In the present paper we review the use of inert gases as anesthetics and neuroprotectants, with particular attention to the clinical use of xenon. We discuss recent advances in understanding the molecular pharmacology of xenon and we highlight specific pharmacological targets that may mediate its actions as an anesthetic and neuroprotectant. We summarize recent in vitro and in vivo studies on the actions of helium and the other inert gases, and discuss their potential to be used as neuroprotective agents.
\end{abstract}

\section{Introduction}

The inert or noble gases helium, neon, argon, krypton and xenon exist as monatomic gases with low chemical reactivity. Considerable attention has focused on the use of xenon as a general anesthetic [1-4] and its potential for use as a neuroprotectant [5-7].

A number of recent studies report that helium may have neuroprotectant and/or cardioprotecant properties [8-13]. Argon also appears to be neuroprotective in certain in vitro and in vivo models $[14,15]$. At first sight it might appear unlikely that inert gases would have any biological activity. Nevertheless, evidence for the biological effects of inert gases emerged from research into the physiological effects of diving. As long ago as the 1930s, nitrogen was shown to be the cause of the narcosis experienced by divers [16,17]. The narcotic effects of nitrogen begin to occur at a depth of about 30 meters (a pressure of $\sim 3 \mathrm{~atm}$ ), and increased with depth, with loss

*Correspondence: r.dickinson@imperial.ac.uk

'Biophysics Section, Blackett Laboratory, Imperial College London, South Kensington, London SW7 2AZ, UK

Full list of author information is available at the end of the article of consciousness occurring at depths of about 100 meters $[18,19]$. Behnke and Yarbrough showed in 1938 that if helium replaced nitrogen in the breathing mixture, the nitrogen narcosis was avoided [20]. Neon is also devoid of narcotic effect [18]. The lighter inert gases helium and neon therefore appear both chemically and biologically inactive, at least at tolerable pressures (see below). Argon and krypton, on the other hand, induce narcosis more potently than nitrogen $[17,21]$ - with the pressures resulting in anesthesia being $15.2 \mathrm{~atm}$ and $4.5 \mathrm{~atm}$, respectively [22]. These heavier inert gases therefore do have biological activity, at least under hyperbaric conditions.

Xenon was predicted to be an anesthetic at atmospheric pressure, based on its relative solubility in fat compared with argon, krypton and nitrogen. An effect of xenon in animals was first shown by Lawrence and colleagues in 1946, who reported sedation, ataxia and other behavioral effects in mice exposed to between 0.40 and 0.78 atm xenon [21]. The anesthetic potency of inert gases follows the Meyer-Overton correlation with solubility in oil or fat (see Figure 1 and Table 1), with xenon being most potent (and most soluble in oil) followed by krypton and argon. Radon is the heaviest of the inert gases and might be predicted to be an anesthetic. Radon is radioactive, however, and exposure to radon - even at very low levels is a health risk [23].

The lighter inert gases neon and helium are not anesthetics $[24,25]$, at least up to the highest pressures $(\sim 100 \mathrm{~atm})$ that can be tolerated before the confounding effects of high-pressure neurological syndrome become pronounced. At these high pressures, the manifestations of high-pressure nervous syndrome include hyperexcitability, tremors and convulsions [26,27], which would act to oppose any sedative or anesthetic effect. The lack of observable anesthetic effects of helium and neon are either due to a lack of biological activity or, alternatively, these gases could have some intrinsic anesthetic potency at high pressures that is counteracted by the effects of high-pressure nervous syndrome. If we make the assumption that these gases do have some intrinsic potency that would be observable in the absence of the 


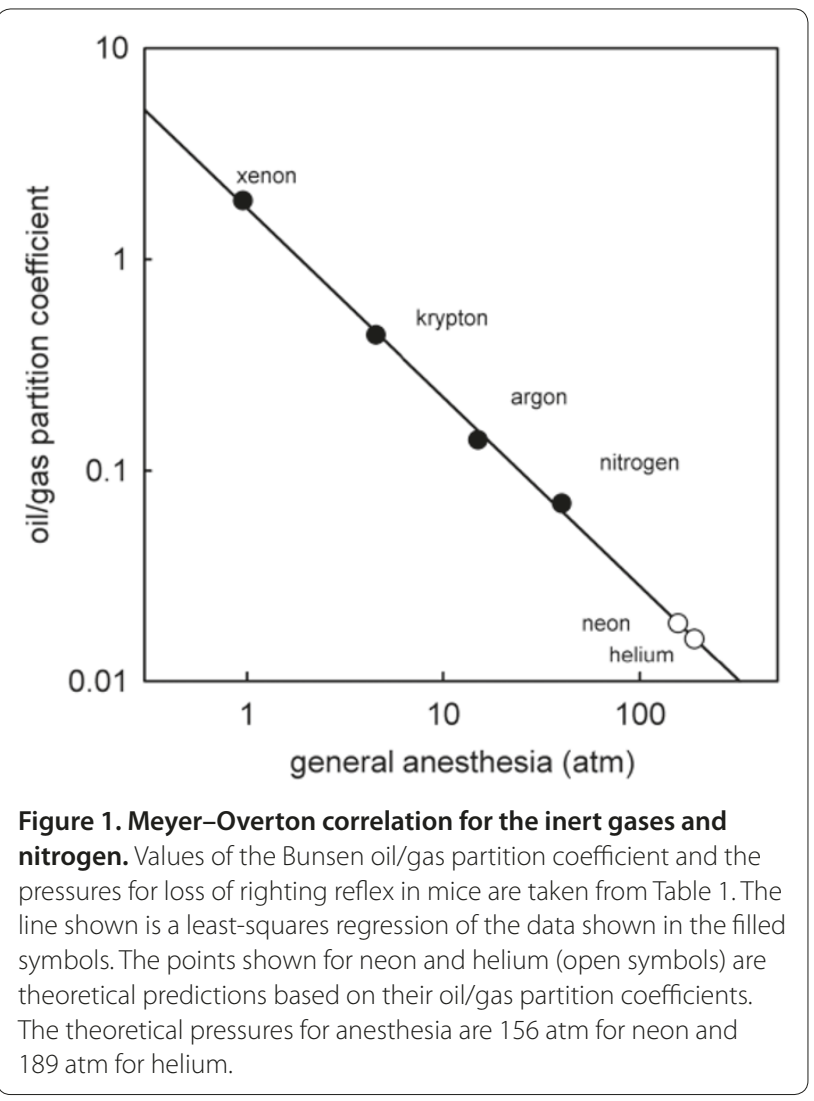

confounding effects of high-pressure nervous syndrome, it is possible to calculate a theoretical anesthetic pressure. Based on the Meyer-Overton correlation and using loss of righting reflex in mice as the anesthetic endpoint, the predicted anesthetic pressures are $156 \mathrm{~atm}$ for neon and $189 \mathrm{~atm}$ for helium (see Figure 1).

\section{Pharmacology of xenon}

Although the general anesthetic properties of xenon have been known since the 1950s, only recently have molecular targets for xenon been identified that could mediate xenon's biological actions. The first target to be identified was the $N$-methyl-D-aspartate (NMDA) receptor when, in 1998, it was shown that xenon inhibited NMDA-evoked currents in cultured hippocampal neurons by $\sim 60 \%$ at a clinically relevant concentration of $80 \%$ xenon [28]. Xenon was also found to inhibit NMDA receptors at glutamatergic hippocampal synapses by $\sim 60 \%$, but to have little effect on synaptic $\alpha$ amino-3-hydroxy-5-methyl-4-isoxazolepropionic acid (AMPA)/kainate receptors [28]. The specificity of xenon for the NMDA-mediated component of the glutamatergic synaptic response, together with the lack of effect at inhibitory $\gamma$-amino-butyric acid (GABA)ergic synapses $[28,29]$, imply that xenon acts postsynaptically.

Another finding consistent with a postsynaptic site of action for xenon is the lack of effect of xenon on $\mathrm{N}$-type voltage-gated calcium channels, which are involved in neurotransmitter release at neuronal synapses [30]. The molecular mechanism by which xenon inhibits the NMDA receptor has now been elucidated [31]. It has been shown that xenon competes for the binding of the co-agonist glycine at the glycine site on the NMDA receptor (Figure 2a). Based on protein crystallographic data, the binding of glycine is proposed to result in domain closure of the NMDA receptor leading to channel opening, and competitive inhibitors are suggested to prevent this domain closure [32]. Xenon therefore possibly stabilizes the open conformation of the domains, thus preventing channel opening.

Interestingly, recent crystallographic data on the binding of xenon to the Annexin $\mathrm{V}$ protein suggest that xenon may disrupt conformational changes in this protein [33]. Consistent with competitive inhibition at the NMDAreceptor glycine site, xenon inhibits the NMDA receptor more potently at low glycine concentrations than at high glycine concentration (Figure $2 b$ ). In addition to competitive inhibition at the glycine site, a Lineweaver-Burk

Table 1. Physical properties of the inert gases and nitrogen

\begin{tabular}{|c|c|c|c|c|c|c|}
\hline Physical property & Helium & Neon & Nitrogen & Argon & Krypton & Xenon \\
\hline Atomic number & 2 & 10 & 7 & 18 & 36 & 54 \\
\hline Atomic mass $(\mathrm{g} / \mathrm{mol})^{a}$ & 4.0 & 20.2 & 14.0 & 39.9 & 83.8 & 131.3 \\
\hline Density $(\mathrm{g} / \mathrm{l})\left(0^{\circ} \mathrm{C}\right)^{\mathrm{a}}$ & 0.1785 & 0.900 & 1.251 & 1.784 & 3.736 & 5.887 \\
\hline Thermal conductivity $(\mathrm{W} / \mathrm{m} / \mathrm{K})(300 \mathrm{~K})^{\mathrm{b}}$ & $0.1499^{a}$ & 0.0491 & $0.0260^{a}$ & 0.0178 & 0.0094 & 0.0056 \\
\hline Polarizability a $\left(\AA^{3}\right)^{c}$ & 0.21 & 0.39 & 1.74 & 1.64 & 2.48 & 4.04 \\
\hline Water/gas partition coefficient at $25^{\circ} \mathrm{C} d$ & 0.0085 & 0.010 & 0.015 & 0.031 & 0.053 & 0.095 \\
\hline Oil/gas partition coefficient at $25^{\circ} \mathrm{C}^{\mathrm{d}}$ & 0.016 & 0.019 & 0.07 & 0.14 & 0.44 & 1.9 \\
\hline General anesthesia (atm) ${ }^{d}$ & Not anesthetic & Not anesthetic & 39 & 15.2 & 4.5 & $\begin{array}{c}0.95 \text { (mouse), } \\
0.6 \text { to } 0.7 \text { (human) }\end{array}$ \\
\hline
\end{tabular}

Partition coefficients are experimentally measured Bunsen coefficients. Anesthetic potency data for nitrogen, argon and krypton are for loss of righting reflex in mice. For xenon, values are given for loss of righting reflex in mice and general anesthesia minimum alveolar concentration in humans (see text for minimum alveolar concentration values). Data compiled from the following sources: ${ }^{\mathrm{a} C R C}$ Handbook of Chemistry \& Physics [107]. ${ }^{b}$ Selovar [108]. Trudell and colleagues [106]. ${ }^{\mathrm{d}}$ Roth and Miller [109]. 
(a)

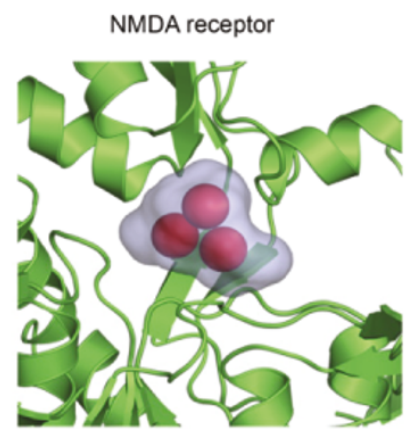

(c)

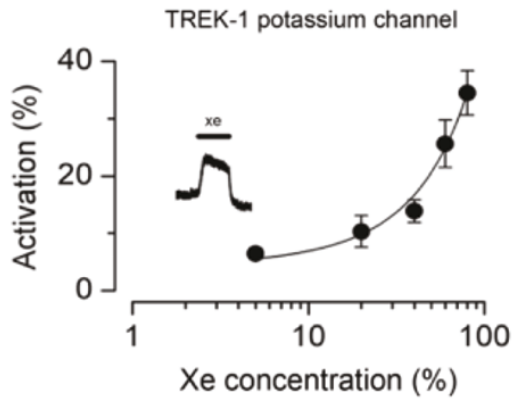

(b)

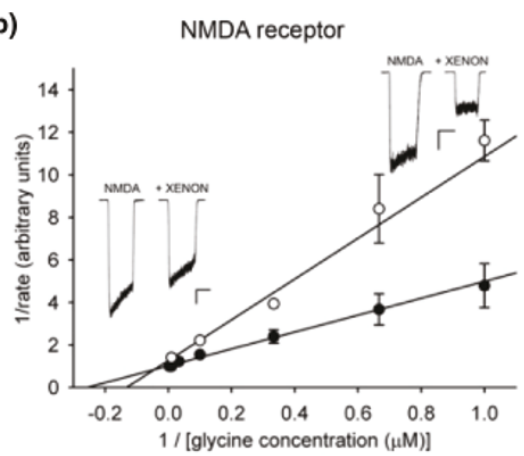

(d)

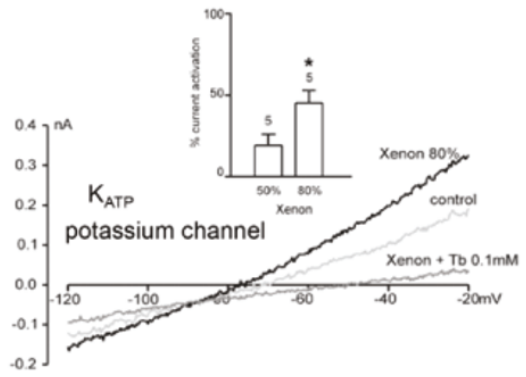

Figure 2. Identified targets for xenon that may mediate xenon anesthesia and neuroprotection. (a) Xenon binds to the N-methyl-D-aspartate (NMDA) receptor at its glycine binding site. (b) Lineweaver-Burk plot showing competitive inhibition of the NMDA receptor by xenon. Inhibition is glycine dependent, with greater inhibition at low glycine concentration ( $1 \mu \mathrm{M})$ (inset upper right) compared with high glycine concentration $(100 \mu \mathrm{M})$ (inset lower left). (c) The two-pore domain potassium channel TREK-1 is activated by xenon in a concentration-dependent manner. Inset: the current activated by $80 \%$ xenon. Horizontal bar, 2-minute application of xenon, the current amplitude is 106 pA. (d) The ATP-sensitive potassium $\left(\mathrm{K}_{\mathrm{ATP}}\right)$ channel is activated by xenon. Main figure shows that $80 \%$ xenon activates $\mathrm{K}_{\mathrm{ATP}}$ and that the current is abolished by $0.1 \mathrm{mM}$ of the specific blocker tolbutamide (Tb). Inset: percentage activation of the current measured at $-20 \mathrm{mV}$ by $50 \%$ and $80 \%$ xenon. ${ }^{*} P<0.05$. Figures adapted from: (a), (b) Dickinson and colleagues [31], (c) Gruss and colleagues [42], and (d) Bantel and colleagues [45].

analysis (Figure $2 \mathrm{~b}$ ) shows that xenon has an additional noncompetitive component of inhibition [31]. It is possible that xenon's mixed competitive and noncompetitive inhibition underlies its beneficial profile compared with other NMDA receptor antagonists.

It was recently reported that xenon inhibits synaptic AMPA receptors in brain slices from the prefrontal cortex and spinal cord to a similar degree as NMDA receptors [34] - in contrast to previous studies that found little or no inhibition of AMPA-mediated synaptic responses in hippocampal neurons $[28,29]$. The extent to which AMPA receptors are inhibited by xenon remains to be clarified. If xenon does inhibit AMPA receptors, however, this inhibition could contribute to xenon anesthesia and neuroprotection.

Unlike most general anesthetics (for example, isoflurane, sevoflurane, propofol, etomidate), xenon has little or no effect on $\mathrm{GABA}_{\mathrm{A}}$ receptors. In cultured hippocampal neurons and mouse fibroblast cells stably expressing $\alpha_{1} \beta_{1} \gamma_{2 L}$ subunits, xenon has no effect on currents elicited by exogenous GABA [28]. Similarly, xenon has no effect on
GABAergic synapses in cultured hippocampal neurons [29]. A study using Xenopus oocytes expressing $\alpha_{1} \beta_{2} \gamma_{2 S}$ subunits, however, reported a small ( 15\%) potentiation of GABAevoked currents by xenon [35]. Whether this reflects differences between Xenopus oocytes and mammalian systems or between different GABA -receptor subunit combinations is not clear. Nevertheless, xenon's effect on $\mathrm{GABA}_{\mathrm{A}}$ receptors is minimal compared with other anesthetics that typically potentiate GABAergic currents by $100 \%$ or more at clinical concentrations [29,36-39].

The identification of xenon as an inhibitor of the NMDA receptor provided the first putative target for xenon anesthesia and prompted the idea that xenon might be neuroprotective (as glutamate excitotoxicity is involved in pathological conditions such as ischemia and traumatic brain injury $[40,41])$. Since then a small number of other targets have been identified that may also play a role in mediating xenon's anesthetic and neuroprotective properties.

The two-pore domain potassium channel TREK-1 is activated by xenon [42] (Figure 2c). Two-pore domain 
potassium channels modulate neuronal excitability by providing a background or leak potassium conductance. Activation of two-pore domain potassium channels will tend to hyperpolarize the cell membrane and reduce neuronal excitability. Volatile anesthetics such as halothane and isoflurane also activate TREK-1 [43]. Studies using TREK-1 knockout animals have implicated this channel in general anesthesia with volatile anesthetics, and in neuroprotection by the fatty acid linolenate [44]. Whether activation of TREK-1 plays a role in mediating anesthesia and neuroprotection with xenon remains to be determined. Nevertheless, TREK-1 is a plausible target for these actions of xenon.

Recently, xenon has been shown to activate another potassium channel, the plasmalemmal ATP-sensitive potassium $\left(\mathrm{K}_{\text {ATP }}\right)$ channel [45]. $\mathrm{K}_{\text {ATP }}$ channels are inhibited by physiological levels of ATP and act as sensors of metabolic activity. In neurons, $\mathrm{K}_{\mathrm{ATP}}$ channels are activated under conditions of physiological stress such as hypoxia. Activation of $\mathrm{K}_{\text {ATP }}$ channels reduces neuronal excitability and is protective against ischemic injury [46]. Clinical concentrations of xenon activate $\mathrm{K}_{\text {ATP }}$ channels by up to $50 \%$ (Figure $2 \mathrm{~d}$ ), and this activation may mediate xenon preconditioning against ischemic injury [45].

Other ion channels that appear to be sensitive to xenon are neuronal nicotinic acetylcholine (nACh) receptors and 5-hydroxytryptamine type $3\left(5-\mathrm{HT}_{3}\right)$ receptors. Neuronal nACh receptors, composed of $\alpha_{4} \beta_{2}$ subunits, and homomeric $\alpha_{7}$ subunits are inhibited by xenon, whereas $\alpha_{4} \beta_{4}$-containing receptors are insensitive to xenon [36,47]. Although nACh receptors are inhibited by a number of anesthetics at clinically relevant concentrations, it is unclear whether this inhibition has any role in mediating general anesthesia. Neuronal $\mathrm{nACh}$ receptors have been implicated in neuroprotection (for a review see [48]). However, it is activation of nACh receptors that is neuroprotective. Hence, inhibition of nACh receptors by xenon is unlikely to play any role in xenon neuroprotection. Xenon inhibits human $5-\mathrm{HT}_{3}$ receptors expressed in Xenopus oocytes by $\sim 65 \%$ at clinical concentrations [49]. The clinical significance of this observation, however, is unclear. While $5-\mathrm{HT}_{3}$ antagonists, such as ondansetron, are used as antiemetics, xenon appears if anything to cause more postoperative nausea and vomiting compared with propofol [50].

\section{Clinical use of xenon}

Xenon was first used as a general anesthetic in the 1950s by Cullen and coworkers in the United States. They reported successful anesthesia in two patients using $80 \%$ xenon, $20 \%$ oxygen. One patient was an 81 -year-old male undergoing orchidectomy, and the other was a 38-yearold female undergoing ligation of the fallopian tubes [51]. This was followed by use in a further five patients undergoing hernioplasty [52]. Loss of consciousness occurred when patients breathed $50 \%$ xenon, and a xenon concentration of 75 to $80 \%$ was used for maintenance of anesthesia during the surgery. Following the definition of minimum alveolar concentration as the standard anesthetic endpoint by Eger and colleagues [53], the value for xenon was determined. In a study of 28 patients, the minimum alveolar concentration of xenon was found to be $71 \%$ [54]. More recent estimates of the xenon minimum alveolar concentration are in the range 63 to $68 \%$ [55,56]. For the next two decades the use of xenon as a general anesthetic remained a curiosity and received little attention.

In the 1990s interest in xenon anesthesia received new impetus as xenon's beneficial clinical properties were further investigated. Lachmann and coworkers found that xenon anesthesia resulted in greater hemodynamic stability compared with nitrous oxide $[57,58]$. The same studies showed xenon to be a profound analgesic, as evidenced by a greatly reduced need for fentanyl analgesia during surgery. On average, patients receiving xenon needed only $20 \%$ of the dose of fentanyl required when nitrous oxide was used instead of xenon [57]. Similar findings were later reported by Nakata and colleagues [59]. A multi-modal experimental pain study in healthy volunteers reported that the analgesic potency of xenon was 1.5 times that of nitrous oxide [60]. Emergence from xenon anesthesia is rapid, with xenon emergence times being only $50 \%$ of the emergence times using nitrous oxide/sevoflurane anesthesia, and the emergence times with xenon are independent of the duration of anesthesia $[61,62]$. These properties of rapid induction and emergence arise from xenon's very low blood/gas partition coefficient of 0.115 [63] and its low solubility in lipids (xenon has an oil/gas partition coefficient of 1.9; Table 1) compared with other inhalational agents. For example, isoflurane has a blood/gas coefficient of 1.4 and an oil/gas partition coefficient of 97 , and for sevoflurane these values are 0.69 and 53, respectively [64].

Xenon's properties of cardiovascular stability, rapid onset and emergence from anesthesia, profound analgesia and the fact that xenon is not metabolized are some of the characteristics of an ideal anesthetic. Xenon would be a useful replacement for nitrous oxide, with the advantage that xenon - being a natural component of the atmosphere - is not a greenhouse gas. Nitrous oxide, on the contrary, is chemically synthesized and is 230 times more potent as a greenhouse gas than carbon dioxide [65]. Furthermore, there are concerns regarding the possible toxic effects of nitrous oxide, particularly in pediatric anesthesia (for reviews see $[66,67]$ ).

The discovery that xenon is an NMDA-receptor antagonist [28] led to the idea that xenon may be neuroprotective. The renewed clinical interest in xenon in the 
past 10 years is due, in large part, to xenon's potential as a neuroprotectant. In 2003 the first multicenter randomized control trial, involving 224 patients in six centers, compared xenon/oxygen with isoflurane/nitrous oxide anesthesia, and concluded that xenon anesthesia is as safe and effective as the isoflurane/nitrous oxide regimen, with the advantage that xenon exhibited more rapid recovery [68]. Another study of 20 patients undergoing coronary artery bypass surgery compared the cardiovascular effects of xenon with nitrous oxide when used to supplement fentanyl-midazolam anesthesia. This study found that xenon provided better hemodynamic stability and preserved left ventricular function better compared with fentanyl-midazolam alone [3].

Studies in both cardiac and noncardiac patients showed that xenon does not impair cardiovascular function and maintains higher arterial pressure compared with propofol [69-71]. A recent multicenter trial of xenon compared with isoflurane found that xenon did not impair left ventricular function while isoflurane significantly decreased global hemodynamic parameters [2].

These clinical data show that xenon is safe and effective as an anesthetic, with some advantages compared with conventional anesthesia regimens. The high cost of xenon and the need for closed-circuit anesthesia with a specialized anesthesia machine, however, will limit xenon's widespread use unless a significant clinical benefit (for example, neuroprotection) can be found.

\section{Xenon neuroprotection}

Overactivation of glutamate receptors is involved in a number of pathological processes. Excessive entry of calcium, mediated by NMDA receptors, triggers biochemical cascades that ultimately lead to neuronal cell death. This neurotoxicity due to overactivation of NMDA receptors was termed excitotoxicity by Olney [72], and is believed to underlie the neuronal injury observed in pathological conditions such as stroke and traumatic brain injury. There has, for some time, been evidence that NMDA-receptor antagonists are neuroprotective in in vitro and in vivo brain injury models [40].

Following the discovery that xenon inhibits NMDA receptors, it was shown that xenon could protect neuronal cell cultures against injury induced by NMDA, glutamate or oxygen-glucose deprivation [6]. The same study showed xenon to be neuroprotective in vivo against neuronal injury caused by subcutaneous injection of $N$ methyl(D,L)-aspartate in rats. Other NMDA-receptor antagonists such as nitrous oxide, ketamine and dizocilpine (MK801) have intrinsic neurotoxicity, but xenon appears devoid of neurotoxic effects $[73,74]$. Xenon has now been shown to afford neuroprotection in a variety of mammalian in vitro and in vivo models, including focal cerebral ischemia (mouse), neonatal asphyxia (mouse), neurocognitive deficit following cardiopulmonary bypass (rat and pig) and traumatic brain injury (mouse) [5,75-81] (Figure 3).

Inhibition of the NMDA receptor by xenon is plausible as a mechanism for xenon neuroprotection. Only very recently, however, has a direct connection between NMDA-receptor antagonism and xenon neuroprotection been demonstrated. Banks and colleagues [7] showed that acute xenon neuroprotection in an in vitro model of hypoxia/ischemia can be reversed by elevating the glycine concentration (Figure 4a), consistent with xenon neuroprotection being mediated by inhibition of the NMDA receptor at its glycine site [31]. Interestingly, xenon appears to act synergistically with the neuroprotective effects of both hypothermia and the volatile anesthetic isoflurane $[76,82]$. Although a mechanistic explanation for this synergism remains to be determined, isoflurane in addition to its well-known actions at the $\mathrm{GABA}_{\mathrm{A}}$ receptor - also competes for glycine at the NMDAreceptor glycine site [31]. The binding of volatile general anesthetics to proteins increases at lower temperatures due to favorable enthalpic interactions, and this increase in binding correlates with the increase in general anesthetic potency observed at lower temperatures [8385]. Whether xenon exhibits similar temperature dependence in its interactions with the targets mediating its anesthetic and neuroprotective effects remains to be elucidated.

In addition to its action as an acute neuroprotectant (when applied during or after the insult), xenon is neuroprotective in preconditioning paradigms. Preconditioning refers to the situation where a neuroprotectant is present before the insult, but not during or after the insult. Exposure to xenon for 2 hours, prior to hypoxia/ ischemia 24 hours later, was shown to result in reduction of injury in cultured neurons and in vivo in neonatal rats $[45,86]$. Inhibition of the NMDA receptor might be thought to be less likely to play any role in xenon preconditioning, as pathological glutamate release occurs only during and after the insult. Since NMDA receptors are not overstimulated before the insult, how their inhibition by xenon could mediate xenon preconditioning is not as clear as in the case of acute xenon neuroprotection. Nevertheless, NMDA receptors are known to couple to many intracellular signaling pathways, so it remains possible that xenon inhibition of normal NMDA-receptor functioning before the insult could trigger some longterm effect that might mediate preconditioning.

Whether the NMDA receptor plays a role in xenon preconditioning remains to be determined. A recent study, however, has identified the ATP-sensitive potassium $\mathrm{K}_{\text {ATP }}$ channel as being involved in xenon preconditioning. Bantel and colleagues showed that xenon preconditioning against hypoxia/ischemia is abolished by 


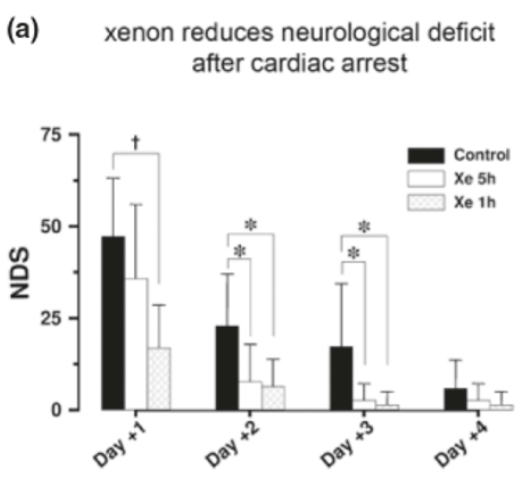

(c)

xenon improves neurological function after cardiopulmonary bypass

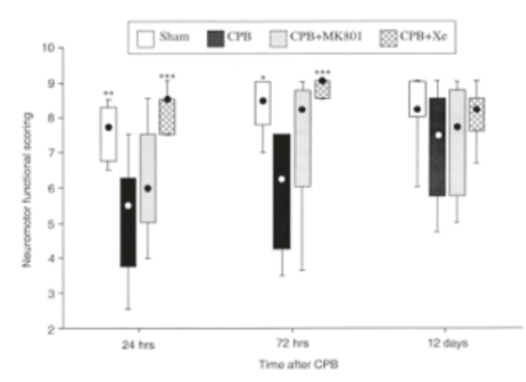

(b)

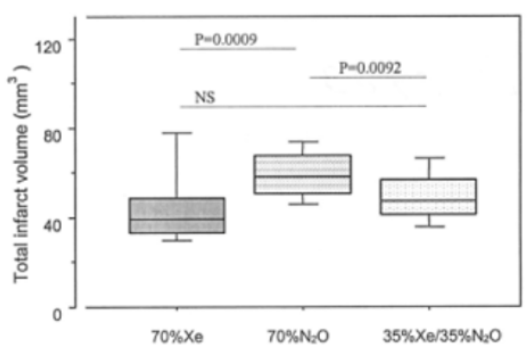

(d)

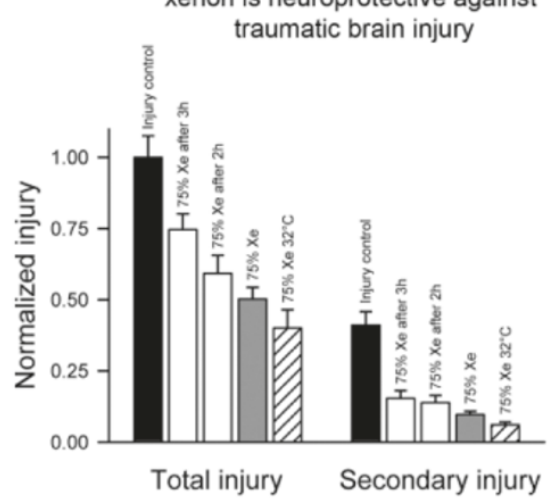

Figure 3. Xenon is neuroprotective in a variety of mammalian in vitro and in vivo models. (a) Xenon treatment after cardiopulmonary resuscitation reduces neurological deficit in a pig model. There is a significant improvement in the neurological deficit score (NDS) in xenontreated animals. $+P<0.01, * P<0.05$. (b) Xenon reduces infarct volume after focal ischemia in mice. Infarct volume after transient middle cerebral artery occlusion is significantly reduced in xenon-treated animals compared with those treated with nitrous oxide. NS, not significant. (c) Xenon improves neurological function following cardiopulmonary bypass (CPB) in a rat model. Xenon-treated animals received $60 \%$ xenon during CPB procedure. ${ }^{*} P<0.05,{ }^{* *} P<0.01$, ${ }^{* * *} P<0.001$. (d) Xenon is neuroprotective in an in vitro model of traumatic brain injury. Xenon (75\%) give significant neuroprotection $(P<0.05)$ when applied immediately after the trauma (grey bars) or after a delay of 2 or 3 hours (white bars). Xenon is particularly effective at reducing the secondary injury that develops in the 72 hours following injury. Figures adapted from: (a) Fries and colleagues [78], (b) Homi and colleagues [5], (c) Ma and colleagues [75], and (d) Coburn and colleagues [77].

the plasmalemmal $\mathrm{K}_{\mathrm{ATP}}$ channel blocker tolbutamide (see Figure 4b) [45], implying a role for the activation of the $\mathrm{K}_{\text {ATP }}$ channel. The mechanism by which transient activation of the $\mathrm{K}_{\text {ATP }}$ channel by xenon results in neuroprotection 24 hours later is not known. There is some evidence to suggest that xenon preconditioning results in an increase in phosphorylated cAMP response element binding protein and the pro-survival proteins B-cell lymphoma 2 and brain-derived neurotrophic factor [86], although a causal link with $\mathrm{K}_{\mathrm{ATP}}$ channels has not been established.

The clinical trials discussed previously have looked at the safety and efficacy of xenon as an anesthetic. Very few trials, however, have as yet directly addressed xenon neuroprotection. Clinical trials are underway, or planned, looking specifically at xenon as a neuroprotectant in cardiopulmonary bypass (a procedure associated with postoperative cognitive deficit), neonatal asphyxia and neurological deficit following cardiac arrest and resuscitation. To date, however, none of these trials have been completed.

A phase 1 trial in patients undergoing coronary artery graft on cardiopulmonary bypass that showed xenon can be safely delivered to these patients has been completed [1]. Two trials have examined postoperative cognitive deficit (POCD) in elderly patients undergoing noncardiac elective surgery, comparing xenon anesthesia with propofol anesthesia $[87,88]$. Neither study found a decreased incidence of POCD in the xenon group compared with the propofol group. Another study looking at POCD in elderly patients undergoing elective surgery found no advantage of xenon compared with desflurane anesthesia [89].

The lack of efficacy in these trials may, partly, be explained by the low numbers of patients resulting in underpowered studies. Only one of the studies involved 


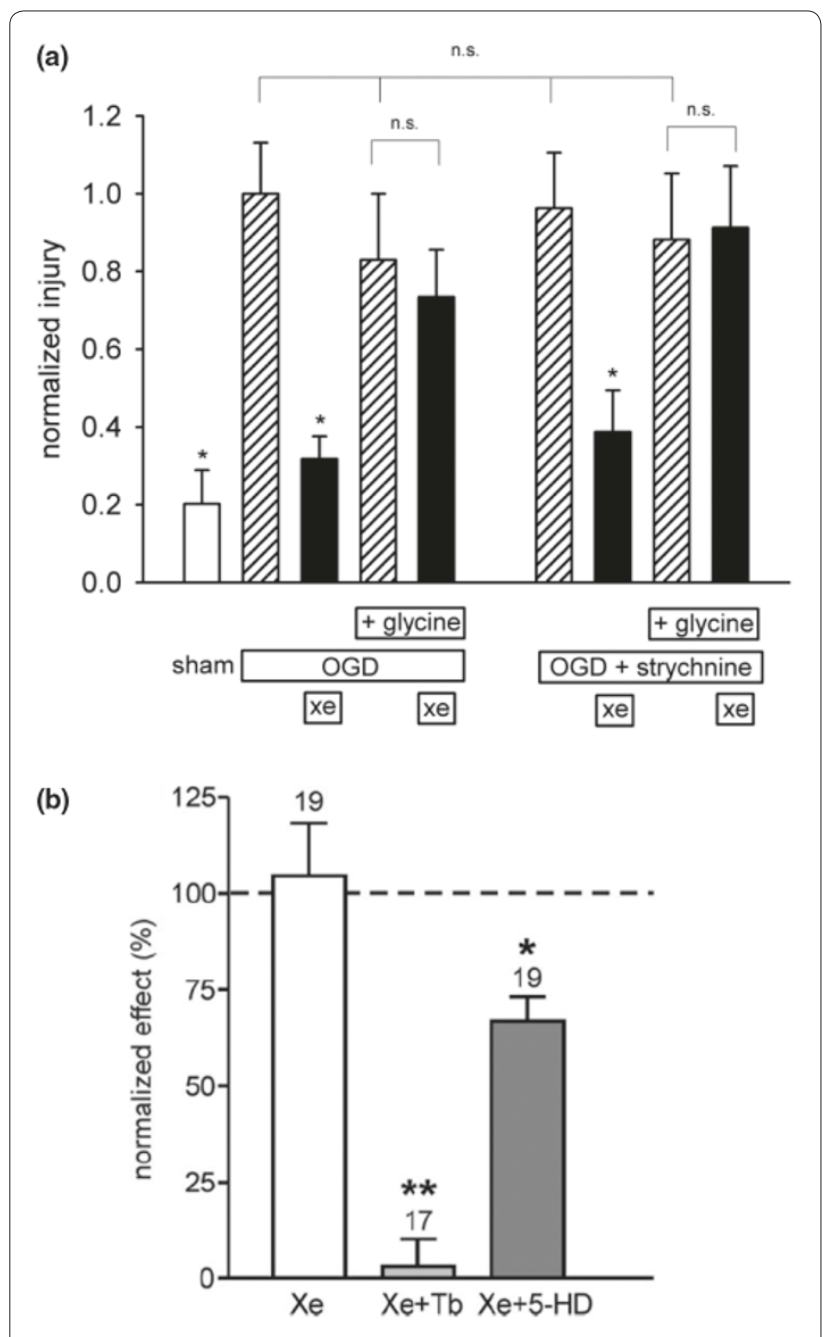

Figure 4. Different targets mediate acute xenon neuroprotection and xenon preconditioning. (a) Acute xenon neuroprotection against hypoxia/ischemia involves the $N$-methyl-Daspartate-receptor glycine site. Acute xenon protection is reversed by adding glycine. Applying 50\% atm xenon after hypoxia/ischemia in the absence of added glycine (black bars) gives robust protection ( $32 \pm 6 \%$ of control injury). However, the protective effect of $50 \%$ atm xenon is abolished in the presence of $100 \mu \mathrm{M}$ glycine. Addition of the inhibitory glycine receptor antagonist strychnine (100 nM) had no effect on control oxygen-glucose deprivation (OGD) with or without glycine, xenon neuroprotection without glycine, or the reversal of xenon neuroprotection by glycine. The error bars are standard errors from an average of 44 slices at each condition. Data have been normalized to the control OGD with no added glycine. *Value significantly different $(P<0.05)$ from control OGD. n.s., not significant. Figure adapted from Banks and colleagues [7]. (b) Xenon preconditioning against hypoxia/ischemia involves the plasmalemmal ATP-sensitive potassium $\left(K_{\text {ATP }}\right)$ channel. Exposure of cultured neurons to $75 \%$ xenon for 2 hours protects cells against hypoxia/ischemia 24 hours later (white bar). This effect is abolished by the plasmalemmal $\mathrm{K}_{\text {ATP }}$ blocker tolbutamide $(\mathrm{Tb})(0.1 \mathrm{mM})$ but not by the mitochondrial $K_{\text {ATP }}$ channel blocker 5-hydroxy-decanoic acid (5-HD) $(0.5 \mathrm{mM}) .{ }^{*} P<0.05,{ }^{* *} P<0.01$. Figure adapted from Bantel and colleagues [45] more than 100 patients [87], and the other two used fewer than 40 patients each. Another confounding factor is that, although POCD is a recognized phenomenon, particularly in the older person, it is not straightforward to quantify POCD. The different studies used different assessment criteria and different times after surgery when assessments were performed. Larger trials will be required to definitively determine whether xenon reduces POCD in elderly patients.

POCD following cardiopulmonary bypass (CPB) is thought to result in part from particulate and gaseous cerebral emboli subsequent to CPB. Concerns have been raised about the potential effects of xenon on gasembolism growth as xenon may increase the size of preexisting gas emboli, but estimates as to the extent of this effect vary widely in the literature. A theoretical study predicted rapid and infinite expansion of $50 \mathrm{nl}$ air bubbles in the presence of $70 \%$ xenon [90]. An experimental study, however, found $50 \%$ xenon to have only a relatively modest effect [91]. Both this study and other experimental studies have compared xenon with nitrous oxide, and show that xenon causes much less expansion of gas bubbles than does nitrous oxide [91-93].

Studies in animal models of CPB have reported differing results regarding the effects of xenon on gas emboli. Grocott and colleagues reported a modest (17\%) increase in the size of large $(\sim 400 \mathrm{nl})$ air bubbles artificially introduced into a bypass circuit in a rat model in the presence of $70 \%$ xenon [93]. Another study using a rat CPB model combined with artificially introduced air bubbles of $300 \mathrm{nl}$ reported that exposure to $56 \%$ xenon resulted in increased infarct volume and neurological deficit compared with nitrogen [94]. A later study by the same group, however, concluded that xenon did not affect neurological or histological outcome [95]. The reasons for these discrepancies are not clear.

It should be noted that the artificial introduction of a small number of relatively large air bubbles into the $\mathrm{CPB}$ circuit does not accurately model the clinical scenario, where it is more likely that bubbles will be small in size but may be numerous. The only human trial that has directly measured embolic load in CPB patients during xenon treatment found that xenon (20 to $50 \%$ ) caused no increase in embolic load [1]. Nevertheless, the issue of whether xenon may increase embolic load should be borne in mind (and monitored) in future clinical trials.

Aside from its potential to reduce POCD, xenon could be argued to be more likely to show a benefit in situations where the potential damage in the absence of any neuroprotection is more severe. In this regard it will be interesting to see whether clinical trials of xenon in neonatal asphyxia show xenon to be neuroprotective, as has been demonstrated in in vivo models of neonatal asphyxia $[76,96]$. 


\section{Use of helium and other inert gases as potential neuroprotectants}

The evidence for the neuroprotective properties of xenon has prompted interest in investigating whether other inert gases have similar potential as neuroprotectants. Helium is the lightest of the inert gases, is not an anesthetic, is much more abundant and is significantly cheaper to produce than xenon. Mixtures of helium and oxygen (heliox) are used in diving to avoid the effects of nitrogen narcosis. Medical use of helium/oxygen has been advocated in patients with respiratory illness. The first use of helium/oxygen in acute asthma patients was in 1934 [97], with the study reporting an alleviation of dyspnea. Recent systematic reviews, however, have concluded that the current evidence does not support use of helium/oxygen in acute asthma or chronic obstructive pulmonary disease $[98,99]$, and helium has not been widely used to treat respiratory illness.

To date there have been relatively few studies investigating the potential of helium as a neuroprotectant, and these have been limited to in vitro and in vivo models. In an in vitro organotypic hippocampal brain slice model of traumatic brain injury, mild hyperbaric helium (0.5 or $1 \mathrm{~atm}$ ) was found to be neuroprotective [77]. This study found that the outcome was significantly worse if nitrogen replaced helium. The authors concluded that the effect of helium was the result of a beneficial effect of pressure per se combined with an attenuation of the deleterious effects of nitrogen [77]. Interestingly, an in vitro model of hypoxic/ischemic injury using the same organotypic brain slice preparation found no effect of $0.5 \mathrm{~atm}$ helium [7]. This may reflect the fact that different mechanisms of injury are activated in these different injury paradigms. Another in vitro study using cultured neurons reported that normobaric helium (75\%) was actually detrimental to neuronal survival after hypoxia/ ischemia [15]. An in vivo study in rats subjected to focal ischemia, however, reported that $75 \%$ helium reduced the infarct volume and improved functional neurological outcome 24 hours after injury [11]. The reasons for the differing findings with helium in these studies are not entirely clear.

Nevertheless, it is interesting to note that these variable effects with helium contrast with the effects observed with xenon, which appears to be neuroprotective in all of these models. While a number of pharmacological targets have been identified for xenon, no targets have been identified for helium.

Helium is considered to be inert and lacking in an intrinsic pharmacological effect; helium is therefore often used as a pressurizing gas in studies of the biological effects of pressure per se $[100,101]$. Compared with xenon, which has neuroprotective effects at concentrations similar to those causing anesthesia, it seems implausible that the nonanesthetic helium would have any pharmacological effect at or near atmospheric pressure. Even if we assume, as predicted by the MeyerOverton correlation, that helium might be anesthetic at $\sim 200$ atm (Figure 1), if helium was neuroprotective at 1 atm it would be acting at 1/200th of its anesthetic concentration. Effects at such low relative concentrations have not been observed for other anesthetic neuroprotectants. Even in the case of xenon, which is neuroprotectant at subanesthetic concentrations as low as $\sim 20 \%$ [76], the ratio of neuroprotectant to anesthetic concentration is only $\sim 1 / 3$. Helium therefore seems unlikely to be acting via a pharmacological mechanism.

An interesting recent study by David and colleagues, however, has identified a probable physical mechanism that may underlie the reported neuroprotective effects of helium [12]. This study in rats found that, at room temperature, $75 \%$ helium resulted in significantly reduced brain infarct size and improved functional neurological outcome when helium treatment took place following middle cerebral artery occlusion. The authors discovered, however, that breathing helium gas below body temperature (for example, $25^{\circ} \mathrm{C}$ ) caused hypothermia in the rats (Figure 5a). Helium was neuroprotective when the inspired temperature was $25^{\circ} \mathrm{C}$, but the neuroprotective effect was abolished when the temperature of the inspired helium was increased to $33^{\circ} \mathrm{C}$ (abolishing the hypothermia) (Figure 5b). The authors conclude that the neuroprotective effects of helium are due to hypothermia.

Neuroprotection via cooling is well established in model systems and is used clinically (for reviews see $[102,103])$. The reason that helium causes hypothermia is due to its high thermal conductivity compared with air. The thermal conductivity of helium is $0.1499 \mathrm{~W} / \mathrm{m} / \mathrm{K}-$ almost six times greater than nitrogen, which has a thermal conductivity of $0.0260 \mathrm{~W} / \mathrm{m} / \mathrm{K}$ (Table 1 ). Breathing helium at a temperature lower than body temperature will hence cause a reduction in core temperature. This phenomenon is recognized in divers breathing heliox mixtures who require heated diving suits and heated gas delivery equipment in order to avoid hypothermia. Xenon, on the contrary, has a thermal conductivity five times lower than nitrogen (see Table 1), and therefore would not result in cooling via this mechanism. In common with other anesthetics, however, xenon exhibits an anesthesiainduced hypothermia. The neuroprotection observed with helium is probably therefore due to helium-induced hypothermia rather than to any pharmacological effect of helium. The cooling effect of helium could also occur in in vitro systems lacking adequate gas-temperature control, and this may explain the variable effects observed in different studies using helium.

The other inert gases - neon, argon and krypton - have received very little attention as potential 

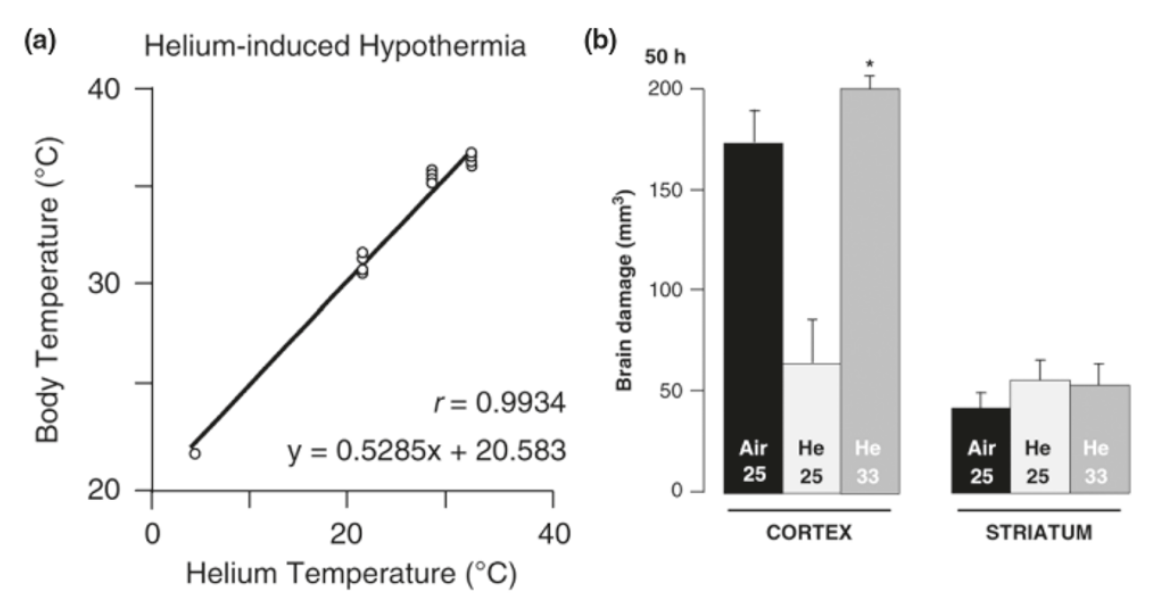

Figure 5. Helium causes hypothermia in rats, which mediates its neuroprotective effect. (a) Breathing $75 \%$ helium at temperatures lower than $37^{\circ} \mathrm{C}$ results in hypothermia. (b) Breathing $75 \%$ helium at $25^{\circ} \mathrm{C}$ following injury protects the cortex against focal ischemic injury (light grey bar). The protective effect of helium is abolished if the gas is warmed to $35^{\circ} \mathrm{C}$ (dark grey bars). The striatum is resistant to both injury and the protective effects of hypothermia (shown on the right). ${ }^{*} P<0.05$. Figures adapted from David and colleagues [12].

neuroprotectants. Argon and krypton are anesthetics under hyperbaric conditions, at $15 \mathrm{~atm}$ and $4.5 \mathrm{~atm}$, respectively, and might be expected to be neuroprotective at these pressures. It is conceivable that argon and krypton could be neuroprotective at atmospheric pressure - by analogy with xenon, which exhibits neuroprotective properties even at $\sim 1 / 3$ of its anesthetic potency. Neon, on the contrary, is not an anesthetic - but based on its oil solubility, neon might be predicted to be an anesthetic at $\sim 160$ atm. By the same argument as above for helium, neon is unlikely to have a pharmacological neuroprotective effect at atmospheric pressures. Neon's thermal conductivity is twice that of nitrogen, hence neon breathing might induce hypothermia. Any effect, however, is likely to be much less than that caused by helium.

Argon does appear to be neuroprotective in certain model systems. In an in vivo study, normobaric argon (25 to $77 \%$ ) increased survival rates of rats exposed to varying degrees of hypoxia [104]. An in vitro study using cochlear organotypic cultures from rats found that argon (74 to 95\%) was protective against hypoxic injury and injury induced by the anticancer drug cisplatin or the antibiotic gentamycin [14]. Another in vitro study using mouse cortical cell cultures found that $75 \%$ argon protected against hypoxic/ischemic injury but that the same concentrations of krypton or neon had no effect [15]. A recent in vitro study has shown that normobaric argon protects mouse hippocampal organotypic cultures against both ischemic and traumatic injury [105]. Argon therefore does indeed appear to be neuroprotective at normobaric pressures. This effect is most probably mediated by a pharmacological mechanism. The thermal conductivity of argon is less than that of nitrogen - hence argon will not cause hypothermia via this physical mechanism, but may cause anesthesia-induced hypothermia at elevated pressures. The reason for the lack of neuroprotective effect of krypton is unclear. To date, however, there has only been a single in vitro study on krypton.

Whether krypton has a neuroprotective effect in other injury paradigms merits further investigation. No molecular targets have as yet been identified that could mediate anesthesia or neuroprotection by argon or krypton. Molecular modeling, however, suggests that the inert gases with anesthetic properties (argon, krypton and xenon) and nitrogen all make similar types of interactions with a model protein cavity [106]. The binding energies of the inert gases can only arise from favorable enthalpic $(\Delta \mathrm{H})$ contributions due to London Dispersion forces (also known as van der Waals interactions) and/or charge-induced dipole interactions. Both of these enthalpy terms are proportional to the polarizability $(\alpha)$ of the gas (Table 1). Relative to a particular standard state, the energy of these favorable enthalpic $(\Delta \mathrm{H})$ terms must be sufficient to overcome the unfavorable entropy term associated with binding. The anesthetic inert gases (argon, krypton and xenon) can be distinguished from the nonanesthetic helium and neon by their greater polarizability [106] (Table 1), which results in larger favorable enthalpic interactions. Xenon, for example, has a value of $\alpha$ of $4.04 \AA^{3}$, which is 19 times greater than that of helium $\left(0.21 \AA^{3}\right)$ and 10 times that of neon $\left(0.39 \AA^{3}\right)$. Argon and krypton have $\alpha$ values of $1.64 \AA^{3}$ and $2.48 \AA^{3}$, respectively, which are eight times and 12 times greater than the value for helium. Therefore it is plausible that 
This article is part of a review series on Gaseous Mediators, edited by Dr Peter Radermacher. Other articles in the series can be found online at http://ccforum.com/series/gaseous_mediators

argon and krypton interact with the same targets as xenon, even if somewhat more weakly. That anesthesia and neuroprotection by the inert gases share similar mechanisms is, therefore, an interesting possibility.

\section{Conclusions}

The present review summarizes studies on the pharmacology and clinical uses of the inert gases as anesthetics and neuroprotectants. Xenon is the only inert gas that is an anesthetic at atmospheric pressure. A relatively small number of pharmacological targets for xenon have been identified that may play a role in xenon anesthesia and neuroprotection; the NMDA receptor, the two-pore domain potassium channel TREK-1 and the $K_{\text {ATP }}$ channel. Xenon has been shown to be an effective neuroprotectant in in vitro and in vivo injury models, and the results of clinical trials to assess xenon's effectiveness as a neuroprotectant in patients are eagerly awaited. The mechanisms involved in xenon neuroprotection are beginning to be understood. There is new evidence that inhibition of the NMDA receptor by xenon mediates acute xenon neuroprotection, and that the $\mathrm{K}_{\mathrm{ATP}}$ channel is involved in xenon preconditioning.

Helium has been shown to be neuroprotective in vivo, but this effect is mediated by helium-induced hypothermia rather than by a pharmacological effect. Even if helium is devoid of pharmacological action, the cooling effect resulting from helium's high thermal conductivity could be exploited clinically. Furthermore, as xenon and hypothermia appear to act synergistically in experimental models, it is possible that the two neuroprotective strategies of xenon and hypothermia could be applied simultaneously using a helium/xenon mixture combined with an appropriate controlled gas-cooling apparatus.

Argon and krypton are anesthetic at elevated pressures, but few studies have investigated neuroprotection by argon and krypton. However, argon appears to be neuroprotective at atmospheric pressure in certain model systems. Further studies are needed to determine whether argon and krypton have potential as neuroprotectants.

\section{Abbreviations}

AMPA, a-amino-3-hydroxy-5-methyl-4-isoxazolepropionic acid $\mathrm{CPB}$, cardiopulmonary bypass; GABA, $\gamma$-aminobutyric acid; $5 \mathrm{HT}_{3^{\prime}}$ 5-hydroxytryptamine type $3 ; \mathrm{K}_{\text {ATp }}$ adenosine triphosphate-sensitive potassium; nACh, nicotinic acetylcholine; NMDA, N-methyl-D-aspartate; POCD, postoperative cognitive dysfunction.

\section{Acknowledgements}

The present work was supported by the European Society for Anaesthesiology (Brussels, Belgium), the Royal College of Anaesthetists (London UK), and Westminster Medical School Research Trust (London, UK).

\section{Competing interests}

NPF has a financial interest in the use of xenon as a neuroprotectant and has been a paid consultant for Air Products and Chemicals Inc. (Allentown, PA, USA) for this activity. RD declares that he has no competing interests.

\section{Author details}

'Biophysics Section, Blackett Laboratory, Imperial College London, South Kensington, London SW7 2AZ, UK. '2Department of Anaesthetics, Pain Medicine \& Intensive Care, Imperial College London, Chelsea and Westminster Campus, Fulham Road, London SW10 9NH, UK.

Published: 12 August 2010

\section{References}

1. Lockwood GG, Franks NP, Downie NA, Taylor KM, Maze M: Feasibility and safety of delivering xenon to patients undergoing coronary artery bypass graft surgery while on cardiopulmonary bypass: phase I study. Anesthesiology 2006, 104:458-465.

2. Wappler F, Rossaint R, Baumert J, Scholz J, Tonner PH, van Aken H, Berendes E, Klein J, Gommers D, Hammerle A, Franke A, Hofmann T, Schulte Esch J: Multicenter randomized comparison of xenon and isoflurane on left ventricular function in patients undergoing elective surgery. Anesthesiology 2007, 106:463-471.

3. Goto T, Hanne P, Ishiguro Y, Ichinose F, Niimi Y, Morita S: Cardiovascular effects of xenon and nitrous oxide in patients during fentanyl-midazolam anaesthesia. Anaesthesia 2004, 59:1178-1183.

4. Goto T, Nakata Y, Ishiguro Y, Niimi Y, Suwa K, Morita S: Minimum alveolar concentration-awake of xenon alone and in combination with isoflurane or sevoflurane. Anesthesiology 2000, 93:1188-1193.

5. Homi HM, Yokoo N, Ma D, Warner DS, Franks NP, Maze M, Grocott HP: The neuroprotective effect of xenon administration during transient middle cerebral artery occlusion in mice. Anesthesiology 2003, 99:876-881.

6. Wilhelm S, Ma D, Maze M, Franks NP: Effects of xenon on in vitro and in vivo models of neuronal injury. Anesthesiology 2002, 96:1485-1491.

7. Banks P, Franks NP, Dickinson R: Competitive inhibition at the glycine site of the $\mathrm{N}$-methyl-D-aspartate receptor mediates xenon neuroprotection against hypoxia-ischemia. Anesthesiology 2010, 112:614-622.

8. Huhn R, Heinen A, Weber NC, Hieber S, Hollmann MW, SchlackW, Preckel B: Helium-induced late preconditioning in the rat heart in vivo. Br J Anaesth 2009, 102:614-619.

9. Huhn R, Heinen A, Weber NC, Kerindongo RP, Oei GT, Hollmann MW, Schlack W, Preckel B: Helium-induced early preconditioning and postconditioning are abolished in obese Zucker rats in vivo. J Pharmacol Exp Ther 2009, 329:600-607.

10. Heinen A, Huhn R, Smeele KM, Zuurbier CJ, Schlack W, Preckel B, Weber NC, Hollmann MW: Helium-induced preconditioning in young and old rat heart: impact of mitochondrial $\mathrm{Ca}^{2+}$-sensitive potassium channel activation Anesthesiology 2008, 109:830-836.

11. Pan Y, Zhang H, VanDeripe DR, Cruz-Flores S, Panneton WM: Heliox and oxygen reduce infarct volume in a rat model of focal ischemia. Exp Neurol 2007, 205:587-590.

12. David HN, Haelewyn B, Chazalviel L, Lecoca M, Degoulet M, Risso JJ, Abraini JH: Post-ischemic helium provides neuroprotection in rats subjected to middle cerebral artery occlusion-induced ischemia by producing hypothermia. $J$ Cereb Blood Flow Metab 2009, 29:1159-1165.

13. Pagel PS, Krolikowski JG, Shim YH, Venkatapuram S, Kersten JR, Weihrauch D, Warltier DC, Pratt Jr, PF: Noble gases without anesthetic properties protect myocardium against infarction by activating prosurvival signaling kinases and inhibiting mitochondrial permeability transition in vivo. Anesth Analg 2007, 105:562-569.

14. Yarin YM, Amarjargal N, Fuchs J, Haupt H, Mazurek B, Morozova SV, Gross J: Argon protects hypoxia-, cisplatin- and gentamycin-exposed hair cells in the newborn rat's organ of Corti. Hear Res 2005, 201:1-9.

15. Jawad N, Rizvi M, Gu J, Adeyi O, Tao G, Maze M, Ma D: Neuroprotection (and lack of neuroprotection) afforded by a series of noble gases in an in vitro model of neuronal injury. Neurosci Lett 2009, 460:232-236.

16. Behnke A, Thomson R, Motley E: The psychologic effects from breathing air at 4 atmospheres pressure. Am J Physiol 1935, 112:554-558.

17. Behnke A, Yarbrough O: Respiratory resistance, oil-water solubility and mental effects of argon compared with helium and nitrogen. Am J Physiol 1939, 126:409-415. 
18. Bennett PB, Rostain JC: Inert gas narcosis. In Bennett and Elliot's Physiology and Medicine of Diving. Edited by Brubakk AO, Neuman TS. Edinburgh: Saunders; 2003:300-322.

19. Rostain JC, Balon N: Recent neurochemical basis of inert gas narcosis and pressure effects. Undersea Hyperb Med 2006, 33:197-204.

20. Behnke A, Yarbrough O: Physiologic studies of helium. US Navy Med Bull 1938 36:542-558.

21. Lawrence $\mathrm{JH}$, Loomis WF, Tobias CA, Turpin FH: Preliminary observations on the narcotic effect of xenon with a review of values for solubilities of gases in water and oils. J Physiol 1946, 105:197-204.

22. Miller KW, Paton WD, Smith EB, Smith RA: Physicochemical approaches to the mode of action of general anesthetics. Anesthesiology 1972, 36:339-351.

23. Gray A, Read S, McGale P, Darby S: Lung cancer deaths from indoor radon and the cost effectiveness and potential of policies to reduce them. BMJ 2009, 338:a3110.

24. Miller KW, Paton WD, Streett WB, Smith EB: Animals at very high pressures of helium and neon. Science 1967, 157:97-98

25. Koblin DD, Fang Z, Eger 2nd, El, Laster MJ, Gong D, lonescu P, Halsey MJ, Trudell $J R$ : Minimum alveolar concentrations of noble gases, nitrogen, and sulfur hexafluoride in rats: helium and neon as nonimmobilizers (nonanesthetics). Anesth Analg 1998, 87:419-424.

26. Lever MJ, Miller KW, Paton WDM, Streett WB, Smith EB: Effects of hydrostatic pressure on mammals. In Proceedings of the IVth Symposium on Underwater Physiology. Edited by Lambertsen CJ. New York: Academic Press; 1971:101-108.

27. Halsey MJ: Effects of high pressure on the central nervous system. Physiol Rev 1982, 62(4 Pt 1):1341-1377.

28. Franks NP, Dickinson R, de Sousa SLM, Hall AC, Lieb ER: How does xenon produce anaesthesia? Nature 1998, 396:324.

29. de Sousa SLM, Dickinson R, Lieb WR, Franks NP: Contrasting synaptic actions of the inhalational general anesthetics isoflurane and xenon. Anesthesiology 2000, 92:1055-1066.

30. White IL, Franks NP, Dickinson R: Effects of isoflurane and xenon on $\mathrm{Ba}^{2+}$ currents mediated by N-type calcium channels. Br J Anaesth 2005, 94:784-790.

31. Dickinson R, Peterson BK, Banks P, Simillis C, Martin JC, Valenzuela CA, Maze M, Franks NP: Competitive inhibition at the glycine site of the N-methyl-Daspartate receptor by the anesthetics xenon and isoflurane: evidence from molecular modeling and electrophysiology. Anesthesiology 2007, 107:756-767.

32. Furukawa $\mathrm{H}$, Gouaux E: Mechanisms of activation, inhibition and specificity: crystal structures of the NMDA receptor NR1 ligand-binding core. EMBO J 2003, 22:2873-2885.

33. Colloc'h N, Sopkova-de Oliveira Santos J, Retailleau P, Vivares D, Bonnete F, Langlois d'Estainto B, Gallois B, Brisson A, Risso JJ, Lemaire M, Prange T, Abraini $J \mathrm{H}$ : Protein crystallography under xenon and nitrous oxide pressure: comparison with in vivo pharmacology studies and implications for the mechanism of inhaled anesthetic action. Biophys J 2007, 92:217-224.

34. Haseneder R, Kratzer S, Kochs E, Mattusch C, Eder M, Rammes G: Xenon attenuates excitatory synaptic transmission in the rodent prefrontal cortex and spinal cord dorsal horn. Anesthesiology 2009, 111:1297-1307.

35. Yamakura T, Chavez-Noriega LE, Harris RA: Subunit-dependent inhibition of human neuronal nicotinic acetylcholine receptors and other ligand-gated ion channels by dissociative anesthetics ketamine and dizocilpine. Anesthesiology 2000, 92:1144-1153.

36. Yamakura T, Harris RA: Effects of gaseous anesthetics nitrous oxide and xenon on ligand-gated ion channels. Comparison with isoflurane and ethanol. Anesthesiology 2000, 93:1095-1101.

37. Tomlin SL, Jenkins A, Lieb WR, Franks NP: Stereoselective effects of etomidate optical isomers on $\gamma$-aminobutyric acid type $A$ receptors and animals. Anesthesiology 1998, 88:708-717.

38. Hall AC, Lieb WR, Franks NP: Stereoselective and non-stereoselective actions of isoflurane on the GABA receptor. Br J Pharmacol 1994, 112:906-910.

39. Jones MV, Harrison NL: Effects of volatile anesthetics on the kinetics of inhibitory postsynaptic currents in cultured rat hippocampal neurons. J Neurophysiol 1993, 70:1339-1349.

40. Choi DW, Koh JY, Peters S: Pharmacology of glutamate neurotoxicity in cortical cell culture: attenuation by NMDA antagonists. J Neurosci 1988 8:185-196.

41. Bullock R, Zauner A, Myseros JS, Marmarou A, Woodward JJ, Young HF: Evidence for prolonged release of excitatory amino acids in severe human head trauma. Relationship to clinical events. Ann N Y Acad Sci 1995
765:290-297

42. Gruss M, Bushell TJ, Bright DP, Lieb WR, Mathie A, Franks NP: Two-pore-domain $\mathrm{K}^{+}$channels are a novel target for the anesthetic gases xenon, nitrous oxide, and cyclopropane. Mol Pharmacol 2004, 65:443-452.

43. Patel AJ, Honore E, Lesage F, Fink M, Romey G, Luzdunski M: Inhalational anesthetics activate two-pore-domain background $\mathrm{K}^{+}$channels. Nat Neurosci 1999, 2:422-426.

44. Heurteaux C, Guy N, Laigle C, Blondeau N, Duprat F, Mazzuca M, Lang Lazdunski L, Widmann C, Zanzouri M, Romey G, Lazdunski M: TREK-1, a K+ channel involved in neuroprotection and general anesthesia. EMBO J 2004, 23:2684-2695.

45. Bantel C, Maze M, Trapp S: Neuronal preconditioning by inhalational anesthetics: evidence for the role of plasmalemmal adenosine triphosphate-sensitive potassium channels. Anesthesiology 2009, 110:986-995

46. Ballanyi K: Protective role of neuronal KATP channels in brain hypoxia. J Exp Biol 2004, 207(Pt 18):3201-3212.

47. Suzuki T, Ueta K, Sugimoto M, Uchida I, Mashimo T: Nitrous oxide and xenon inhibit the human (alpha 7) 5 nicotinic acetylcholine receptor expressed in Xenopus oocyte. Anesth Analg 2003, 96:443-448, table of contents.

48. Bencherif M: Neuronal nicotinic receptors as novel targets for inflammation and neuroprotection: mechanistic considerations and clinical relevance. Acta Pharmacol Sin 2009, 30:702-714.

49. Suzuki T, Koyama H, Sugimoto M, Uchida I, Mashimo T: The diverse actions of volatile and gaseous anesthetics on human-cloned 5-hydroxytryptamine3 receptors expressed in Xenopus oocytes. Anesthesiology 2002, 96:699-704.

50. Coburn M, Kunitz O, Apfel CC, Hein M, Fries M, Rossaint R: Incidence of postoperative nausea and emetic episodes after xenon anaesthesia compared with propofol-based anaesthesia. Br J Anaesth 2008, 100:787-791.

51. Cullen SC, Gross EG: The anesthetic properties of xenon in animals and human beings, with additional observations on krypton. Science 1951, 113:580-582

52. Pittinger CB, Moyers J, Cullen SC, Featherstone RM, Gross EG: Clinicopathologic studies associated with xenon anesthesia. Anesthesiology 1953, 14:10-17.

53. Eger 2nd El, Saidman $\sqcup$, Brandstater B: Minimum alveolar anesthetic concentration: a standard of anesthetic potency. Anesthesiology 1965 26:756-763.

54. Cullen SC, Eger 2nd El, Cullen BF, Gregory P: Observations on the anesthetic effect of the combination of xenon and halothane. Anesthesiology 1969, 31:305-309.

55. Nakata Y, Goto T, Ishiguro Y, Terui K, Kawakami H, Santo M, Niimi Y, Morita S: Minimum alveolar concentration (MAC) of xenon with sevoflurane in humans. Anesthesiology 2001, 94:611-614

56. Eger 2nd El, Laster MJ, Gregory GA, Katoh T, Sonner JM: Women appear to have the same minimum alveolar concentration as men: a retrospective study. Anesthesiology 2003, 99:1059-1061.

57. Boomsma F, Rupreht J, Man in 't Veld AJ, de Jong FH, Dzoljic M, Lachmann B: Haemodynamic and neurohumoral effects of xenon anaesthesia. A comparison with nitrous oxide. Anaesthesia 1990, 45:273-278.

58. Lachmann B, Armbruster S, Schairer W, Landstra M, Trouwborst A, Van Daal GJ, Kusuma A, Erdmann W: Safety and efficacy of xenon in routine use as an inhalational anaesthetic. Lancet 1990, 335:1413-1415.

59. Nakata Y, Goto T, Saito H, Ishiguro Y, Terui K, Kawakami H, Tsuruta Y, Niimi Y, Morita S: Plasma concentration of fentanyl with xenon to block somatic and hemodynamic responses to surgical incision. Anesthesiology 2000, 92:1043-1048

60. Petersen-Felix S, Luginbuhl M, Schnider TW, Curatolo M, Arendt-Nielsen L, Zbinden AM: Comparison of the analgesic potency of xenon and nitrous oxide in humans evaluated by experimental pain. Br J Anaesth 1998, 81:742-747.

61. Luttropp HH, Thomasson R, Dahm S, Persson J, Werner O: Clinical experience with minimal flow xenon anesthesia. Acta Anaesthesio/ Scand 1994, 38:121-125.

62. Goto T, Saito H, Nakata Y, Uezono S, Ichinose F, Morita S: Emergence times from xenon anaesthesia are independent of the duration of anaesthesia. $\mathrm{Br} J$ Anaesth 1997, 79:595-599.

63. Goto T, Suwa K, Uezono S, Ichinose F, Uchiyama M, Morita S: The blood-gas partition coefficient of xenon may be lower than generally accepted. $\mathrm{Br} J$ Anaesth 1998, 80:255-256.

64. Yentis SM, Hirsch NP, Smith GB: Anaesthesia and Intensive Care A-Z An Encyclopaedia of Priciples and Practice. Edinburgh: Elsevier; 2004:271. 
65. Goto T: Is there a future for xenon anesthesia? Can J Anaesth 2002 49:335-338.

66. Sanders RD, Weimann J, Maze M: Biologic effects of nitrous oxide: a mechanistic and toxicologic review. Anesthesiology 2008, 109:707-722.

67. Baum VC: When nitrous oxide is no laughing matter: nitrous oxide and pediatric anesthesia. Paediatr Anaesth 2007, 17:824-830.

68. Rossaint R, Reyle-Hahn M, Schulte Am Esch J, Scholz J, Scherpereel P, Vallet B, Giunta F, Del Turco M, Erdmann W, Tenbrinck R, Hammerle AF, Nagele P: Multicenter randomized comparison of the efficacy and safety of xenon and isoflurane in patients undergoing elective surgery. Anesthesiology 2003, 98:6-13.

69. Coburn M, Kunitz O, Baumert JH, Hecker K, Haaf S, Zuhlsdorff A, Beeker T, Rossaint R: Randomized controlled trial of the haemodynamic and recovery effects of xenon or propofol anaesthesia. $\mathrm{Br}$ J Anaesth 2005, 94:198-202.

70. Bein B, Turowski P, Renner J, Hanss R, Steinfath M, Scholz J, Tonner PH: Comparison of xenon-based anaesthesia compared with total intravenous anaesthesia in high risk surgical patients. Anaesthesia 2005, 60:960-967.

71. Baumert JH, Hein M, Hecker KE, Satlow S, Neef P, Rossaint R: Xenon or propofol anaesthesia for patients at cardiovascular risk in non-cardiac surgery. Br J Anaesth 2008, 100:605-611.

72. Olney JW: Brain lesions, obesity, and other disturbances in mice treated with monosodium glutamate. Science 1969, 164:719-721.

73. Ma D, Wilhelm S, Maze M, Franks NP: Neuroprotective and neurotoxic properties of the 'inert' gas, xenon. Br J Anaesth 2002, 89:739-746.

74. Nagata A, Nakao Si S, Nishizawa N, Masuzawa M, Inada T, Murao K, Miyamoto $\mathrm{E}$, Shingu K: Xenon inhibits but $\mathrm{N}_{2} \mathrm{O}$ enhances ketamine-induced c-Fos expression in the rat posterior cingulate and retrosplenial cortices. Anesth Analg 2001, 92:362-368.

75. Ma D, Yang H, Lynch J, Franks NP, Maze M, Grocott HP: Xenon attenuates cardiopulmonary bypass-induced neurologic and neurocognitive dysfunction in the rat. Anesthesiology 2003, 98:690-698.

76. Ma D, Hossain M, Chow A, Arshad M, Battson RM, Sanders RD, Mehmet H, Edwards AD, Franks NP, Maze M: Xenon and hypothermia combine to provide neuroprotection from neonatal asphyxia. Ann Neurol 2005, 58:182-193.

77. Coburn M, Maze M, Franks NP: The neuroprotective effects of xenon and helium in an in vitro model of traumatic brain injury. Crit Care Med 2008 36:588-595

78. Fries M, Nolte KW, Coburn M, Rex S, Timper A, Kottmann K, Siepmann K, Hausler M, Weis J, Rossaint R: Xenon reduces neurohistopathological damage and improves the early neurological deficit after cardiac arrest in pigs. Crit Care Med 2008, 36:2420-2426

79. Thoresen M, Hobbs CE, Wood T, Chakkarapani E, Dingley J: Cooling combined with immediate or delayed xenon inhalation provides equivalent long-term neuroprotection after neonatal hypoxia-ischemia. I Cereb Blood Flow Metab 2009, 29:707-714

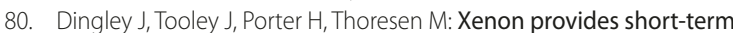
neuroprotection in neonatal rats when administered after hypoxiaischemia. Stroke 2006, 37:501-506.

81. Abraini JH, David HN, Lemaire M: Potentially neuroprotective and therapeutic properties of nitrous oxide and xenon. Ann N Y Acad Sci 2005 1053:289-300.

82. Ma D, Hossain M, Rajakumaraswamy N, Franks NP, Maze M: Combination of xenon and isoflurane produces a synergistic protective effect against oxygen-glucose deprivation injury in a neuronal-glial co-culture model. Anesthesiology 2003, 99:748-751.

83. Dickinson R, Franks NP, Lieb WR: Thermodynamics of anesthetic/protein interactions. Temperature studies on firefly luciferase. Biophys J 1993, 64:1264-1271.

84. McKenzie JD, Calow P, Clyde J, Miles A, Dickinson R, Lieb WR, Franks NP: Effects of temperature on the anaesthetic potency of halothane, enflurane and ethanol in Daphnia magna (Cladocera: Crustacea). Comp Biochem Physiol C 1992, 101:15-19.

85. Dickinson R, Lieb WR, Franks NP: The effects of temperature on the interactions between volatile general anaesthetics and a neuronal nicotinic acetylcholine receptor. Br J Pharmacol 1995, 116:2949-2956. A published erratum appears in Br J Pharmacol 1996, 117:1369.

86. Ma D, Hossain M, Pettet GK, Luo Y, Lim T, Akimov S, Sanders RD, Franks NP Maze M: Xenon preconditioning reduces brain damage from neonatal asphyxia in rats. J Cereb Blood Flow Metab 2006, 26:199-208.
87. Hocker J, Stapelfeldt C, Leiendecker J, Meybohm P, Hanss R, Scholz J, Bein B: Postoperative neurocognitive dysfunction in elderly patients after xenon versus propofol anesthesia for major noncardiac surgery: a doubleblinded randomized controlled pilot study. Anesthesiology 2009, 110:1068-1076.

88. Rasmussen LS, SchmehI W, Jakobsson J: Comparison of xenon with propofol for supplementary general anaesthesia for knee replacement: a randomized study. Br J Anaesth 2006, 97:154-159.

89. Coburn M, Baumert JH, Roertgen D, Thiel V, Fries M, Hein M, Kunitz O, Fimm B, Rossaint R: Emergence and early cognitive function in the elderly after xenon or desflurane anaesthesia: a double-blinded randomized controlled trial. Br J Anaesth 2007, 98:756-762

90. Sta Maria N, Eckmann DM: Model predictions of gas embolism growth and reabsorption during xenon anesthesia. Anesthesiology 2003, 99:638-645.

91. Benavides R, Maze M, Franks NP: Expansion of gas bubbles by nitrous oxide and xenon. Anesthesiology 2006, 104:299-302.

92. Lockwood G: Expansion of air bubbles in aqueous solutions of nitrous oxide or xenon. Br J Anaesth 2002, 89:282-286.

93. Grocott HP, Sato Y, Homi HM, Smith BE: The influence of xenon, nitrous oxide and nitrogen on gas bubble expansion during cardiopulmonary bypass. Eur J Anaesthesiol 2005, 22:353-358.

94. Jungwirth B, Gordan ML, Blobner M, Schmehl W, Kochs EF, Mackensen GB: Xenon impairs neurocognitive and histologic outcome after cardiopulmonary bypass combined with cerebral air embolism in rats. Anesthesiology 2006, 104:770-776.

95. Jungwirth B, Kellermann K, Blobner M, SchmehI W, Kochs EF, Mackensen GB: Cerebral air emboli differentially alter outcome after cardiopulmonary bypass in rats compared with normal circulation. Anesthesiology 2007, 107:768-775.

96. Martin JL, Ma D, Hossain M, Xu J, Sanders RD, Franks NP, Maze M: Asynchronous administration of xenon and hypothermia significantly reduces brain infarction in the neonatal rat. Br J Anaesth 2007, 98:236-240.

97. Barach AL: Use of helium as a new therapetic gas. Proc Soc Exp Biol Med 1934, 32:462-464

98. Rodrigo CJ, Pollack CV, Rodrigo C, Rowe BH: Heliox for non-intubated acute asthma patients. Cochrane Database Syst Rev 2006, 4:CD002884.

99. Colebourn CL, Barber V, Young JD: Use of helium-oxygen mixture in adult patients presenting with exacerbations of asthma and chronic obstructive pulmonary disease: a systematic review. Anaesthesia 2007, 62:34-42.

100. Miller KW, Wilson MW, Smith RA: Pressure resolves two sites of action of inert gases. Mol Pharmacol 1978, 14:950-959.

101. Miller KW, Wilson MW: The pressure reversal of a variety of anesthetic agents in mice. Anesthesiology 1978, 48:104-110.

102. MacLellan CL, Clark DL, Silasi G, Colbourne F: Use of prolonged hypothermia to treat ischemic and hemorrhagic stroke. J Neurotrauma 2009, 26:313-323.

103. Dietrich WD, Atkins CM, Bramlett HM: Protection in animal models of brain and spinal cord injury with mild to moderate hypothermia. J Neurotrauma 2009, 26:301-312.

104. Pavlov BN, Grigoriev Al, Smolin W, Komordin GM, Sokolov GM, Ramazanov RR, Spirkov PS, Soldatov PE, Vdovin AV, Buravkova LB, Diachenko Al, llyin VK Investigations of Different Hyperoxic, Hypoxic and Normoxic Oxygen-Argon Gaseous Mixtures under Different Barometric Pressure and Respiration Periods, in High Pressure Biology and Medicine. Edited by Bennet PB, Demchenko L, Marquis RE. Rochester, MN: University of Rochester Press; 1997:133-142.

105. Loetscher PD, Rossaint J, Rossaint R, Weis J, Fries M, Fahlenkamp A, Ryang YM, Grottke O, Coburn M: Argon: neuroprotection in in vitro models of cerebra ischemia and traumatic brain injury. Crit Care 2009, 13:R206.

106. Trudell JR, Koblin DD, Eger 2nd El: A molecular description of how noble gases and nitrogen bind to a model site of anesthetic action. Anesth Analg 1998, 87:411-418

107. Weast RC, Astle MJ (Eds): CRC Handbook of Chemistry \& Physics. 60th edition. Boca Raton, FL: CRC Press; 1980

108. Selover TB (Ed): Thermophysical Properties of Neon, Argon, Krypton and Xenon. Washington, DC: Hemisphere Publishing; 1988.

109. Roth SH, Miller KW (Eds): Molecular and Cellular Mechanisms of Anesthetics. London: Plenum; 1986.

doi:10.1186/cc9051

Cite this article as: Dickinson R, Franks NP: Bench-to-bedside review:

Molecular pharmacology and clinical use of inert gases in anesthesia and neuroprotection. Critical Care 2010, 14:229. 